\title{
Opening Noise in the Indian Stock Market: Analysis at Individual Stock Level
}

\author{
Faisal Nazir Zargar, Dilip Kumar \\ Indian Institute of Management, Kashipur, India \\ Email: faisal.fpm2015@iimkashipur.ac.in,dksic212@gmail.com
}

How to cite this paper: Zargar, F.N. and Kumar, D. (2019) Opening Noise in the Indian Stock Market: Analysis at Individual Stock Level. Theoretical Economics Letters, 9, 21-32.

https://doi.org/10.4236/tel.2019.91003

Received: October 3, 2018

Accepted: January 7, 2019

Published: January 10, 2019

Copyright ( 2019 by author(s) and Scientific Research Publishing Inc. This work is licensed under the Creative Commons Attribution International License (CC BY 4.0).

http://creativecommons.org/licenses/by/4.0/

(c) (i) Open Access

\begin{abstract}
This is an econometric study of noise in the financial markets, based on the Indian stock market. Historically, the role \& impact of noise traders in the financial markets has been assumed to be minimal or negligible since noise traders should lose money when trading against rational arbitrageurs. However, Shiller et al. [1] argue that there is little reason to believe that noise traders are unimportant and some reason to suspect that rational arbitrageurs dominate the financial markets. Moreover, De Long et al. [2] have developed formal models that allow for the survival of noise traders. Like any other systematic risk, the risk brought in by the noise traders, due to their random sentiments, should be priced. In this paper, we propose an "opening noise trading model" in which the opening price of the stock contains a component of noise that is assumed to be orthogonal to the true price change caused by the arrival of new information. We also provide evidence of the opening stock price containing noise on an everyday basis among all the Nifty stocks. Furthermore, we have shown how to estimate the share of noise in the opening price.
\end{abstract}

\section{Keywords}

Noise Trading, Financial Markets, Arbitrageurs, Asset Pricing, Market Efficiency

\section{Introduction}

This paper is an econometric study of opening noise in the financial markets, based on the Indian stock market. An "opening noise trading model" (which is an unobserved-components model) is proposed in this paper in which the opening stock price contains a component of noise that is assumed to be orthogonal to the true price change caused by the arrival of information. Within the 
framework of [3] and based on the observed properties of the Indian stock market, the unobserved components model has been proposed. The main property of the Indian stock market data is that the opening stock price contains some noise on an everyday basis. Observable opening and closing prices are used to define the close-to-close return (CCR), overnight return (ONR), and the daytime return (DTR). The assumption, in this model, is that the overnight return is the true price plus some opening noise. Similarly, the daytime return is defined as the true price change during trading hours minus some opening noise. Furthermore, the close to close return, defined as the sum of the overnight return and the daytime return, will be free of noise. We find that noise plays an important role in a way that opening stock price contains some noise on an everyday basis among all the NIFTY stocks.

"Noise traders" are those market participants who trade in the security market without considering the use of finance fundamentals, follow trends, exhibit poor market timing, and tend to underreact or overreact to bad and good news. Noise traders play a very significant role in the literature of finance. The AFA presidential address of [4] is dedicated to the beneficial effects of "noise" on capital markets, concluding that the noise trading is very essential for providing the liquidity to the security markets. Noise trading has been identified by and [5] as the base for the limits of arbitrage literature, arguing that noise trading prevents prices from converging to fundamental asset values and introduces risks that inhibit arbitrageurs. The importance of noise trading in financial markets has gained a lot of attention, however, its precise role in financial markets is still debatable, and over whether society is well advised to ignore the noise trading altogether due to its inconsequential nature in affecting capital market outcomes, or to limit it by taxation or other means.

Two strands of the literature emerged in the 1980s which partially tried to explain this confusion and thereby the term "noise traders" has been given very different interpretation by both. The terms "noise traders" and "liquidity traders" are used interchangeably in the market microstructure literature by researchers to describe traders who do not possess any fundamental information (see e.g., [3] [6]). However, the motives of these liquidity traders are often left unspecified; the justification for the changes in traders' optimal portfolio holdings and their trading is generally assumed to be some liquidity needs or hedging. Alternatively, there are reasons for trading other than hedging, liquidity shock, and fundamental information, and this argument is championed by the limits-to-arbitrage literature. As Shleifer [7] labeled this literature as the "noise trader approach to finance", and have adopted the term "noise traders" to explain \& capture behavioral causes for trading that are not captured by the standard explanations.

It is reasonable to conjecture that traders who simply have a taste for trading or who trade due to psychological biases might behave differently from those who are motivated by liquidity shocks or hedging. In his presidential address, Fisher Black was careful to differentiate between these two types of traders, stat- 
ing that "People who usually trade on noise are indulged in trading even though from an objective point of view they would be better off not trading. Perhaps the most obvious reason could be that they think the noise they are trading on is information. Or perhaps they just like to trade".

In this paper, we seek to clarify the market impact and role of noise traders especially in India's emerging stock market at the individual stock level. More specifically, we aim to quantify the proportion of noise in the opening stock price on daily basis. To provide a sketch of our main empirical results, the new Noise Trading Model reports the maximum of 57\% noise share in the opening price and the minimum of $27 \%$. In other words, noise that is accumulated during the non-trading hours plays a significant role in the opening of the day. This implies that the informed traders in the Indian stock market can be more vulnerable to the noise at the beginning of the trading day. The current paper makes two important contributions to the existing literature on noise trading. The first is that this is the first empirical model to quantify the share of noise in the opening price. Second, the paper has significant implications for investors, portfolio managers, and traders as the stock-market participants are the first to benefit. Therefore, the traders can carefully plan their trading strategies by taking into account the opening noise in their respective econometric models.

The remainder of the paper is organized as follows. Section 2 briefs out the literature. Section 3 introduces the model. In Section 4, we describe the data used and discuss the empirical findings. Finally, Section 5 offers the concluding remarks and directions for future research.

\section{Literature Review}

Trading takes place when a particular asset is being assigned different values by different market agents/participants. Following [4] and [8], there are two categories of traders that are present in the capital market: noise traders and information (sophisticated) traders. Moreover, Shefrin and Statman [8] argue that the sophisticated or information traders act \& take their decisions on the basis of fundamental information and rationally process that information. The term "noise traders" has become an inherent expression and appears very frequently in the popular financial websites. There are a number of studies that have shown trading on information are profitable, including [9] [10] [11] [12] [13]. Although the noise trading literature has been growing rapidly since 2000, unlike other behavioral finance segments the literature related to noise trading is relatively thin. Lately, the participation of noise traders in the capital markets have been identified as a major source of volatility, giving rise to a risk which has been termed as the "noise trader risk". Black [4] provides a definition for noise traders but fails to develop a model that captures the effects of noise trading.

Kyle [3] introduces a theoretical framework where the model has three kinds of traders: random noise traders (who trade randomly), a single risk neutral insider (having access to private information regarding the ex-post-liquidation value of the risky asset), and competitive risk-neutral market makers (setting 
price efficiently given the information they have about quantities traded by others). He considered that the informed trader (insider) makes a positive profit by exploiting the information he possesses, where the noise traders provide a camouflage for the informed trader from the market makers. In this model, there is some noise in the opening stock price, but the information of the informed trader is gradually incorporated into prices the way he trades, thus leaving the closing price noise-free. In this paper, we make use of this defining property for our novel "opening noise trading model."

Previous empirical studies exploring the behavior of the stock price at the opening of the day, includes [14] and [15]. The former paper explored the dynamic properties of overnight return (ONR) and day time return (DTR) for the FTSE 100 index. The study involved two time horizons: electronic trading implementation on the London Stock Exchange (LSE), and the stock market crash of October 1987. The latter paper analyzed the different components of the daytime return (DTR), overnight (ONR), and the close to close return (CCR). The paper discusses the properties of these different types of returns for listed stocks on NYSE. In particular, they report that the correlation between overnight return (ONR) and the daytime return (DTR) is insignificant. This finding motivates us to explore the same relationship in the context of the Indian stock market.

\section{Methodology}

\subsection{Model Specification}

Let $P_{t}^{o}$ be the opening price and $P_{t}^{c}$ the closing price of a stock on day $t$. Now, let's define the total return into two components, overnight return (ONR) and the daytime return (DTR). In other words, the close to close return is the sum of day time return and the overnight return.

$$
\begin{gathered}
C C R_{t}=\ln \left(P_{t}^{c} / P_{t-1}^{c}\right) \\
D T R_{t}=\ln \left(P_{t}^{c} / P_{t}^{o}\right) \\
O N R_{t}=\ln \left(P_{t}^{o} / P_{t-1}^{c}\right)
\end{gathered}
$$

where $C C R_{t}, D T R_{t}$ and $O N R_{t}$ are the close to close return, daytime return and overnight return, respectively. We assume that the news released during the trading day related to both the individual firm and the market is incorporated in the closing price, in keeping with [3]. The traders evaluate the information that comes after the trading hours with some noise because given that the market is closed, there is no possible way for them to infer each other's private value. Therefore, there will be some opening noise early in the trading day.

Let's denote the overnight true price change on day $t$ by $T O N R_{t}$, the true price change during the trading day $t$ by $T D T R_{t}$ and the opening noise on day $t$ by $O N$. We assume henceforth that $T O N R_{t}, T D T R_{t}$ and $O N$ are uncorrelated with one another for a given day $\mathrm{t}$ and also that they are uncorrelated across days. 
In other words, we assume that there is no noise in the closing stock price and, therefore as implication the close-to-close return is uncorrelated over time.

Moreover, our goal is to better understand the behavior of noise in stock prices in the Indian market, we propose the following unobserved components model defined as follows:

$$
\begin{gathered}
C C R_{t}=T D T R_{t}+T O N R_{t} \\
O N R_{t}=T O N R_{t}+O N \\
D T R_{t}=T D T R_{t}-O N
\end{gathered}
$$

From Equation (4), we have

$$
\operatorname{Var}\left(C C R_{t}\right)=\operatorname{Var}\left(T D T R_{t}\right)+\operatorname{Var}\left(\operatorname{TONR}_{t}\right)
$$

From Equation (5), we have

$$
\operatorname{Var}\left(O N R_{t}\right)=\operatorname{Var}\left(\operatorname{TONR}_{t}\right)+\operatorname{Var}\left(O N_{t}\right)
$$

Similarly, from Equation (6), we have

$$
\operatorname{Var}\left(D T R_{t}\right)=\operatorname{Var}\left(T D T R_{t}\right)+\operatorname{Var}\left(O N_{t}\right)
$$

Solving for these three equations, we get

$$
\begin{gathered}
\operatorname{Var}\left(T O N R_{t}\right)=\frac{\left[\operatorname{Var}\left(C C R_{t}\right)+\operatorname{Var}\left(O N R_{t}\right)-\operatorname{Var}\left(D T R_{t}\right)\right]}{2} \\
\operatorname{Var}\left(\operatorname{TDTR}_{t}\right)=\frac{\left[\operatorname{Var}\left(C C R_{t}\right)+\operatorname{Var}\left(D T R_{t}\right)-\operatorname{Var}\left(O N R_{t}\right)\right]}{2} \\
\operatorname{Var}\left(O N_{t}\right)=\frac{\left[\operatorname{Var}\left(O N R_{t}\right)+\operatorname{Var}\left(D T R_{t}\right)-\operatorname{Var}\left(C C R_{t}\right)\right]}{2}
\end{gathered}
$$

\subsection{Opening Noise Share}

Let's have look at the $\beta$ from a regression of the close-to-close return (CCR) on the overnight return (ONR):

$$
C C R_{t}=\alpha+\beta * O N R_{t}+\text { error term, }
$$

where

$$
\beta=\frac{\operatorname{Cov}\left(C C R_{t}, O N R_{t}\right)}{\sigma_{O N R_{t}}^{2}}
$$

Now, since $C C R_{t}=D T R_{t}+O N R_{t}$, we have that:

$$
\begin{gathered}
\beta=\frac{\operatorname{Cov}\left(O N R_{t}, D T R_{t}\right)+\operatorname{Cov}\left(O N R_{t}, O N R_{t}\right)}{\sigma_{O N R_{t}}^{2}} \\
\beta=\frac{\operatorname{Cov}\left(O N R_{t}, D T R_{t}\right)}{\sigma_{O N R_{t}}^{2}}+1
\end{gathered}
$$

Also,

$$
\operatorname{Cov}\left(O N R_{t}, D T R_{t}\right)=\operatorname{Cov}\left(T O N R_{t}+O N, T D T R_{t}-O N\right)=-\sigma_{O N}^{2}
$$

Combining these two, we have 


$$
\begin{aligned}
& \beta=1-\frac{\sigma_{O N}^{2}}{\sigma_{O N R_{t}}^{2}} \\
& 1-\beta=\frac{\sigma_{O N}^{2}}{\sigma_{O N R_{t}}^{2}}
\end{aligned}
$$

The ratio in the RHS of the equation gives us the ratio of the variance of the noise in the opening price to that of the overnight return. If we can estimate the earlier regression and find the values of $(1-\beta)$ it will give us the proportion of variance in the opening price due to noise, what we briefly call the noise share in the opening price.

\section{Data and Empirical Results}

Our data consists of the constituents of the S\&P CNX Nifty index from January 2000 to May 2016.

Daily opening, high, low, and closing (OHLC) prices are used for the empirical analysis. The total data points are 2988. The missing data is replaced by the average of the previous five days. The Nifty 50 Index is a well-diversified index, consisting of fifty liquid stocks from 22 sectors. NSE500 index data for the same time frame is also used for comparison. The Bloomberg was used to extract the open, high, low and close stock prices.

In Table 1, we report the summary statistics for the overnight return (ONR), daytime return (DTR) and close-to-close return (CCR). For the details of individual companies, refer to the Appendix, Table A1. As we can see from Table 1, the average overnight return is $+0.20 \%$, whereas the average daytime return is $-0.14 \%$ and so, the average close-to-close return is $+0.06 \%$.

This pattern of the mean of ONR being positive while the mean of DTR being negative is true at the level of the individual companies as well, with a few exceptions, such as Bharat Heavy Electricals Ltd, Bajaj Auto and HDFC whose DTR has a positive mean, as reported in Table A1. Furthermore, we can see from Table 1 that the average volatility of the overnight return is $1.53 \%$, compared to $2.51 \%$ for the close-to-close return.

Now we turn to the estimation of the noise share in the opening price, with the summary of our estimates reported in Table 2 . The individual company-wise values are reported in Table A2. As we can see from Table 2, the share of noise in the opening price is on average 57\%, with the minimum being $27 \%$ (for Dr. Reddy's Laboratories Ltd.) and the maximum is 95\% (for Ambuja Cements Ltd.). This finding makes it clear that approximately half the variance of the opening price change is due to noise.

Table 3 talks about the ratios of Var (TDTR) \& Var (TONR), Var (ON) \& Var (TDTR) and Var (ON) \& Var (TONR). The value of the ratio of the Var (TDTR) \& Var (TONR) is higher (19) which implies we are observing more volatility in the daytime as compared to the overnight. Moreover, we can see that the contribution of the variance of opening noise is more in case of TONR (0.03) 
Table 1. Summary statistics.

\begin{tabular}{ccccccc}
\hline & \multicolumn{3}{c}{$\mu$} & & \multicolumn{2}{c}{$\Sigma$} \\
\hline & $O N R_{t}$ & $D T R_{t}$ & $C C R_{t}$ & $O N R_{t}$ & $D T R_{t}$ & $C C R_{t}$ \\
\hline Min & $-0.13 \%$ & $-0.42 \%$ & $-0.06 \%$ & $1.00 \%$ & $1.89 \%$ & $1.73 \%$ \\
Max & $0.53 \%$ & $0.21 \%$ & $0.13 \%$ & $2.38 \%$ & $3.22 \%$ & $3.24 \%$ \\
Mean & $0.20 \%$ & $-0.14 \%$ & $0.06 \%$ & $1.53 \%$ & $2.57 \%$ & $2.51 \%$ \\
S.D. & $0.10 \%$ & $0.11 \%$ & $0.04 \%$ & $0.29 \%$ & $0.37 \%$ & $0.40 \%$ \\
N & 2988 & 2988 & 2988 & 2988 & 2988 & 2988 \\
\hline
\end{tabular}

Table 2. Summary of noise share.

\begin{tabular}{cc}
\hline & Noise Share \\
\hline Min & $26.99 \%$ \\
Max & $95.03 \%$ \\
Mean & $56.74 \%$ \\
S.D. & $12.95 \%$ \\
\hline
\end{tabular}

Table 3. Ratios of variances for indices.

\begin{tabular}{cccc}
\hline & Var (TDTR)/Var (TONR) & Var (ON)/Var (TDTR) & $\operatorname{Var}(\mathrm{ON}) / \operatorname{Var}(\mathrm{TONR})$ \\
\hline NIFTY & 18.982 & 0.001 & 0.0319 \\
NSE500 & 3.442 & 0.021 & 0.074 \\
\hline
\end{tabular}

as compared to the contribution of the variance of opening noise to TDTR (0.001), which implies that the opening noise diminishes as it reaches the closing of the trading day.

\section{Conclusions \& Further Research}

In this paper, we have proposed a new model for capturing the opening noise. We also have provided the evidence that opening stock price contains noise on an everyday basis among all the Nifty companies. The two broad implications of noise are:

- Noise allows for speculative trading to occur.

- Noise is an indicator of the market inefficiency.

Because people disagree about the future, they trade speculatively thereby making different predictions about the commodity prices and the fate of companies, including other economic variables. These disagreements among investors stem from the fact that every investor interprets data or information subjectively and differently. But since all the world's markets are complex, not all of the market data is "information". The problem of discerning the real information from the noise stems from the fact that many of the daily fluctuations we see in the market are random rather than any meaningful trends. This is the reason why trading happens in the market; because it is a zero-sum game, if every per- 
son knew everything then no speculative trade would occur. In the real life we observe that trades occur as a kind of bet on what is noise and what is information, and generally, the technologically advanced and the more skillful gambler wins.

Noise is everywhere in the market and people make it all the time. Black argues that the econometrics is filled with noise in the form of mismeasurements and unobservables. It doesn't matter that how many variables you put in a model; there are always many more variables to add and the variables you have will always have an error. This is how noise manifests in econometrics. The researchers can build upon this and demonstrate how to profit from the market inefficiency the noise creates.

For the purpose of practicing quant, our study finds contribution in suggesting a trading strategy based on the overnight return (ONR). Based on our study, we suggest that the traders in the Indian stock market shorten the stock at the beginning of the day and lengthen the same stock at the end of the day when the overnight return (ONR) is positive, and when the ONR is negative, buy at the beginning and sell at the end. Despite its simplicity, this trading strategy is highly profitable, because the market is inefficient, due to the significant presence of noise at the opening.

\section{Conflicts of Interest}

The authors declare no conflicts of interest regarding the publication of this paper.

\section{References}

[1] Shiller, R.J., Fischer, S. and Friedman, B.M. (1984) Stock Prices and Social Dynamics. Brookings Papers on Economic Activity, 1984, 457-510. https://doi.org/10.2307/2534436

[2] De Long, J.B., Shleifer, A., Summers, L.H. and Waldmann, R.J. (1990) Noise Trader Risk in Financial Markets. Journal of Political Economy, 98, 703-738. https://doi.org/10.1086/261703

[3] Kyle, A.S. (1985) Continuous Auctions and Insider Trading. Econometrica: Journal of the Econometric Society, 53, 1315-1335. https://doi.org/10.2307/1913210

[4] Black, F. (1986) Noise. The Journal of Finance, 41, 528-543. https://doi.org/10.1111/j.1540-6261.1986.tb04513.x

[5] Shleifer, A. and Vishny, R.W. (1997) The Limits of Arbitrage. The Journal of Finance, 52, 35-55. https://doi.org/10.1111/j.1540-6261.1997.tb03807.x

[6] Glosten, L.R. and Milgrom, P.R. (1985) Bid, Ask and Transaction Prices in a Specialist Market with Heterogeneously Informed Traders. Journal of Financial Economics, 14, 71-100. https://doi.org/10.1016/0304-405X(85)90044-3

[7] Shleifer, A. and Summers, L.H. (1990) The Noise Trader Approach to Finance. Journal of Economic Perspectives, 4, 19-33. https://doi.org/10.1257/jep.4.2.19

[8] Shefrin, H. and Statman, M. (1994) Behavioral Capital Asset Pricing Theory. Journal of Financial and Quantitative Analysis, 29, 323-349.

https://doi.org/10.2307/2331334 
[9] Gervais, S., Kaniel, R. and Mingelgrin, D.H. (2001) The High-Volume Return Premium. The Journal of Finance, 56, 877-919. https://doi.org/10.1111/0022-1082.00349

[10] Vachadze, G. (2001) Recovery of Hidden Information from Stock Price Data: A Semiparametric Approach. Journal of Economics and Finance, 25, 243-258. https://doi.org/10.1007/BF02745887

[11] Pritamani, M. and Singal, V. (2001) Return Predictability Following Large Price Changes and Information Releases. Journal of Banking \& Finance, 25, 631-656. https://doi.org/10.1016/S0378-4266(00)00091-1

[12] Atkins, A.B. and Basu, S. (1995) The Effect of After-Hours Announcements on the Intraday U-Shaped Volume Pattern. Journal of Business Finance \& Accounting, 22, 789-809. https://doi.org/10.1111/j.1468-5957.1995.tb00389.x

[13] Penman, S.H. (1987) The Distribution of Earnings News over Time and Seasonalities in Aggregate Stock Returns. Journal of Financial Economics, 18, 199-228. https://doi.org/10.1016/0304-405X(87)90039-0

[14] Masulis, R.W. and Ng, V.K. (1995) Overnight and Daytime Stock-Return Dynamites on the London Stock Exchange: The Impacts of "Big Bang" and the 1987 Stock-Market Crash. Journal of Business \& Economic Statistics, 13, 365-378. https://doi.org/10.1080/07350015.1995.10524612

[15] Wang, F.Z., Shieh, S.-J., Havlin, S. and Eugene Stanley, H. (2009) Statistical Analysis of the Overnight and Daytime Return. Physical Review E, 79, Article ID: 056109. https://doi.org/10.1103/PhysRevE.79.056109 


\section{Appendix}

Table A1. Summary statistics for individual companies.

\begin{tabular}{|c|c|c|c|c|c|c|}
\hline & \multicolumn{3}{|c|}{ M } & \multicolumn{3}{|c|}{$\sigma$} \\
\hline & ONR & DTR & CCR & ONR & DTR & CCR \\
\hline ACC IS Equity & $0.167 \%$ & $-0.124 \%$ & $0.044 \%$ & $1.260 \%$ & $2.460 \%$ & $2.328 \%$ \\
\hline ACEM IS Equity & $0.186 \%$ & $-0.145 \%$ & $0.041 \%$ & $1.348 \%$ & $2.399 \%$ & $2.305 \%$ \\
\hline ADSEZ IS Equity & $0.187 \%$ & $-0.187 \%$ & $0.000 \%$ & $1.521 \%$ & $2.979 \%$ & $2.904 \%$ \\
\hline APNT IS Equity & $0.109 \%$ & $-0.009 \%$ & $0.101 \%$ & $1.536 \%$ & $2.099 \%$ & $1.732 \%$ \\
\hline ARBP IS Equity & $0.319 \%$ & $-0.243 \%$ & $0.076 \%$ & $1.671 \%$ & $3.010 \%$ & $2.928 \%$ \\
\hline AXSB IS Equity & $0.529 \%$ & $-0.417 \%$ & $0.112 \%$ & $2.206 \%$ & $3.210 \%$ & $2.948 \%$ \\
\hline BHARTI IS Equity & $0.321 \%$ & $-0.241 \%$ & $0.079 \%$ & $1.452 \%$ & $2.533 \%$ & $2.468 \%$ \\
\hline BHEL IS Equity & $0.211 \%$ & $-0.169 \%$ & $0.042 \%$ & $1.278 \%$ & $2.630 \%$ & $2.716 \%$ \\
\hline BHIN IS Equity & $-0.132 \%$ & $0.208 \%$ & $0.081 \%$ & $1.594 \%$ & $2.590 \%$ & $2.289 \%$ \\
\hline BJAUT IS Equity & $0.078 \%$ & $0.031 \%$ & $0.111 \%$ & $1.316 \%$ & $2.186 \%$ & $2.088 \%$ \\
\hline BOB IS Equity & $0.241 \%$ & $-0.184 \%$ & $0.057 \%$ & $1.855 \%$ & $2.976 \%$ & $2.858 \%$ \\
\hline BOS IS Equity & $0.202 \%$ & $-0.108 \%$ & $0.093 \%$ & $1.662 \%$ & $2.088 \%$ & $1.876 \%$ \\
\hline BPCL IS Equity & $0.215 \%$ & $-0.158 \%$ & $0.058 \%$ & $1.560 \%$ & $2.785 \%$ & $2.718 \%$ \\
\hline CIPLA IS Equity & $0.222 \%$ & $-0.189 \%$ & $0.034 \%$ & $1.389 \%$ & $2.214 \%$ & $2.093 \%$ \\
\hline COAL IS Equity & $0.059 \%$ & $-0.071 \%$ & $-0.012 \%$ & $1.005 \%$ & $1.891 \%$ & $1.887 \%$ \\
\hline DRRD IS Equity & $0.186 \%$ & $-0.192 \%$ & $-0.006 \%$ & $2.084 \%$ & $2.280 \%$ & $2.682 \%$ \\
\hline EIM IS Equity & $0.309 \%$ & $-0.180 \%$ & $0.129 \%$ & $2.375 \%$ & $3.178 \%$ & $2.877 \%$ \\
\hline GAIL IS Equity & $0.417 \%$ & $-0.328 \%$ & $0.088 \%$ & $1.618 \%$ & $2.625 \%$ & $2.450 \%$ \\
\hline GRASIM IS Equity & $0.057 \%$ & $0.007 \%$ & $0.064 \%$ & $1.211 \%$ & $2.291 \%$ & $2.216 \%$ \\
\hline HCLT IS Equity & $0.310 \%$ & $-0.367 \%$ & $-0.058 \%$ & $1.752 \%$ & $3.220 \%$ & $3.241 \%$ \\
\hline HDFC IS Equity & $0.072 \%$ & $0.053 \%$ & $0.125 \%$ & $1.283 \%$ & $2.344 \%$ & $2.346 \%$ \\
\hline HDFCB IS Equity & $0.121 \%$ & $-0.034 \%$ & $0.086 \%$ & $1.349 \%$ & $2.176 \%$ & $2.123 \%$ \\
\hline HMCL IS Equity & $0.106 \%$ & $-0.044 \%$ & $0.062 \%$ & $1.369 \%$ & $2.358 \%$ & $2.244 \%$ \\
\hline HNDL IS Equity & $0.155 \%$ & $-0.147 \%$ & $0.008 \%$ & $1.700 \%$ & $2.856 \%$ & $2.721 \%$ \\
\hline HUVR IS Equity & $0.135 \%$ & $-0.103 \%$ & $0.032 \%$ & $1.053 \%$ & $2.033 \%$ & $1.994 \%$ \\
\hline ICICIBC IS Equity & $0.237 \%$ & $-0.168 \%$ & $0.069 \%$ & $1.772 \%$ & $2.816 \%$ & $2.903 \%$ \\
\hline IDEA IS Equity & $0.165 \%$ & $-0.152 \%$ & $0.013 \%$ & $1.379 \%$ & $2.747 \%$ & $2.651 \%$ \\
\hline IIB IS Equity & $0.355 \%$ & $-0.267 \%$ & $0.088 \%$ & $1.919 \%$ & $3.196 \%$ & $3.101 \%$ \\
\hline INFO IS Equity & $0.099 \%$ & $-0.061 \%$ & $0.038 \%$ & $1.492 \%$ & $2.404 \%$ & $2.556 \%$ \\
\hline ITC IS Equity & $0.139 \%$ & $-0.073 \%$ & $0.066 \%$ & $1.105 \%$ & $2.088 \%$ & $2.016 \%$ \\
\hline KMB IS Equity & $0.261 \%$ & $-0.158 \%$ & $0.103 \%$ & $2.055 \%$ & $3.175 \%$ & $3.160 \%$ \\
\hline LPC IS Equity & $0.355 \%$ & $-0.271 \%$ & $0.084 \%$ & $1.912 \%$ & $2.839 \%$ & $2.670 \%$ \\
\hline LT IS Equity & $0.243 \%$ & $-0.189 \%$ & $0.054 \%$ & $1.263 \%$ & $2.435 \%$ & $2.529 \%$ \\
\hline MM IS Equity & $0.205 \%$ & $-0.146 \%$ & $0.058 \%$ & $1.424 \%$ & $2.614 \%$ & $2.627 \%$ \\
\hline
\end{tabular}




\section{Continued}

\begin{tabular}{ccccccc}
\hline MSIL IS Equity & $0.131 \%$ & $-0.031 \%$ & $0.100 \%$ & $1.345 \%$ & $2.389 \%$ & $2.242 \%$ \\
NTPC IS Equity & $0.163 \%$ & $-0.140 \%$ & $0.022 \%$ & $1.091 \%$ & $2.008 \%$ & $1.976 \%$ \\
ONGC IS Equity & $0.199 \%$ & $-0.156 \%$ & $0.043 \%$ & $1.440 \%$ & $2.402 \%$ & $2.341 \%$ \\
PWGR IS Equity & $0.111 \%$ & $-0.092 \%$ & $0.019 \%$ & $1.372 \%$ & $2.125 \%$ & $2.017 \%$ \\
RIL IS Equity & $0.195 \%$ & $-0.130 \%$ & $0.065 \%$ & $1.455 \%$ & $2.281 \%$ & $2.300 \%$ \\
SBIN IS Equity & $0.204 \%$ & $-0.152 \%$ & $0.052 \%$ & $1.289 \%$ & $2.374 \%$ & $2.387 \%$ \\
SUNP IS Equity & $0.155 \%$ & $-0.058 \%$ & $0.098 \%$ & $1.637 \%$ & $2.465 \%$ & $2.288 \%$ \\
TATA IS Equity & $0.257 \%$ & $-0.226 \%$ & $0.032 \%$ & $1.930 \%$ & $2.843 \%$ & $3.038 \%$ \\
TCS IS Equity & $0.183 \%$ & $-0.102 \%$ & $0.080 \%$ & $1.212 \%$ & $2.040 \%$ & $2.048 \%$ \\
TECHM IS Equity & $0.228 \%$ & $-0.171 \%$ & $0.056 \%$ & $1.539 \%$ & $2.835 \%$ & $2.722 \%$ \\
TPWR IS Equity & $0.229 \%$ & $-0.173 \%$ & $0.056 \%$ & $1.390 \%$ & $2.627 \%$ & $2.606 \%$ \\
TTMT IS Equity & $0.227 \%$ & $-0.167 \%$ & $0.060 \%$ & $1.535 \%$ & $2.770 \%$ & $2.833 \%$ \\
UTCEM IS Equity & $0.178 \%$ & $-0.091 \%$ & $0.087 \%$ & $1.520 \%$ & $2.380 \%$ & $2.177 \%$ \\
WIPRO IS Equity & $0.168 \%$ & $-0.150 \%$ & $0.018 \%$ & $1.661 \%$ & $2.840 \%$ & $2.918 \%$ \\
YES IS Equity & $0.249 \%$ & $-0.144 \%$ & $0.105 \%$ & $1.639 \%$ & $3.025 \%$ & $3.039 \%$ \\
\hline
\end{tabular}

Table A2. Noise share.

\begin{tabular}{ll}
\hline & Noise Share \\
\hline ACC IS Equity & 0.69889151 \\
ACEM IS Equity & 0.95034648 \\
ADSEZ IS Equity & 0.69550231 \\
APNT IS Equity & 0.79773095 \\
ARBP IS Equity & 0.58776031 \\
AXSB IS Equity & 0.66546243 \\
BHARTI IS Equity & 0.57675429 \\
BHEL IS Equity & 0.36001389 \\
BHIN IS Equity & 0.78860927 \\
BJAUT IS Equity & 0.62091395 \\
BOB IS Equity & 0.59975337 \\
BOS IS Equity & 0.65257791 \\
BPCL IS Equity & 0.57614297 \\
CIPLA IS Equity & 0.63557508 \\
COAL IS Equity & 0.50818609 \\
DRRD IS Equity & 0.26988735 \\
EIM IS Equity & 0.66145242 \\
GAIL IS Equity & 0.66936981 \\
\hline GRSIM IS Equity & 0.61454726 \\
\hline &
\end{tabular}




\section{Continued}

\begin{tabular}{|c|c|}
\hline HCLT IS Equity & 0.47783780 \\
\hline HDFC IS Equity & 0.49683572 \\
\hline HDFCB IS Equity & 0.56328682 \\
\hline HMCL IS Equity & 0.64023000 \\
\hline HNDL IS Equity & 0.63075601 \\
\hline HUVR IS Equity & 0.57008818 \\
\hline ICICIBC IS Equity & 0.42109029 \\
\hline IDEA IS Equity & 0.63542615 \\
\hline IIB IS Equity & 0.58160237 \\
\hline INFO IS Equity & 0.33002558 \\
\hline ITC IS Equity & 0.62169547 \\
\hline KMB IS Equity & 0.51098980 \\
\hline LPC IS Equity & 0.62697504 \\
\hline LT IS Equity & 0.35343761 \\
\hline MM IS Equity & 0.48322757 \\
\hline MSIL IS Equity & 0.68803893 \\
\hline NTPC IS Equity & 0.55368482 \\
\hline ONGC IS Equity & 0.57020473 \\
\hline PWGR IS Equity & 0.61852222 \\
\hline RIL IS Equity & 0.47935338 \\
\hline SBIN IS Equity & 0.48148091 \\
\hline SUNP IS Equity & 0.65682504 \\
\hline TATA IS Equity & 0.34650794 \\
\hline TCS IS Equity & 0.48862340 \\
\hline TECHM IS Equity & 0.63269124 \\
\hline TPWR IS Equity & 0.52766931 \\
\hline TTMT IS Equity & 0.42501196 \\
\hline UTCEM IS Equity & 0.70066368 \\
\hline WIPRO IS Equity & 0.41790085 \\
\hline YES IS Equity & 0.48386644 \\
\hline
\end{tabular}

